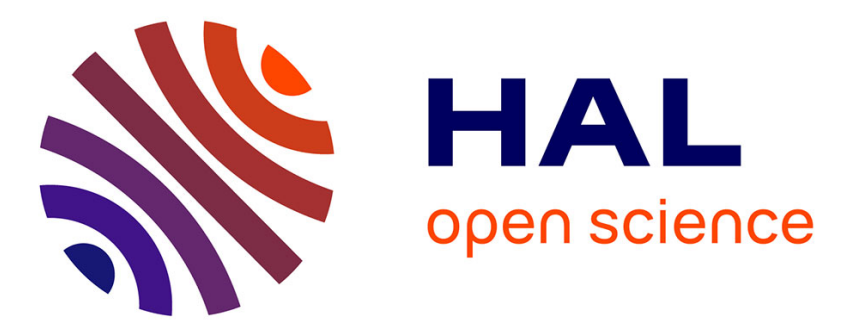

\title{
Model-based approaches for interoperability of next generation enterprise information systems: state of the art and future challenges
}

Gregory Zacharewicz, Saikou Diallo, Yves Ducq, Carlos Agostinho, Ricardo Jardim-Gonçalves, Hassan Bazoun, Zhongjie Wang, Guy Doumeingts

\section{To cite this version:}

Gregory Zacharewicz, Saikou Diallo, Yves Ducq, Carlos Agostinho, Ricardo Jardim-Gonçalves, et al.. Model-based approaches for interoperability of next generation enterprise information systems: state of the art and future challenges. Information Systems and E-Business Management, 2016, 10.1007/s10257-016-0317-8 . hal-01321032

\section{HAL Id: hal-01321032 https://hal.science/hal-01321032}

Submitted on 25 May 2016

HAL is a multi-disciplinary open access archive for the deposit and dissemination of scientific research documents, whether they are published or not. The documents may come from teaching and research institutions in France or abroad, or from public or private research centers.
L'archive ouverte pluridisciplinaire HAL, est destinée au dépôt et à la diffusion de documents scientifiques de niveau recherche, publiés ou non, émanant des établissements d'enseignement et de recherche français ou étrangers, des laboratoires publics ou privés. 


\title{
Model-based approaches for interoperability of next generation enterprise information systems: state of the art and future challenges
}

\author{
Gregory Zacharewicz ${ }^{1} \cdot$ Saikou Diallo $^{2}$. \\ Yves Ducq $^{2}$ - Carlos Agostinho ${ }^{3}$ - Ricardo Jardim-Goncalves ${ }^{3}$. \\ Hassan Bazoun ${ }^{4}$ Zhongjie Wang ${ }^{5}$ Guy Doumeingts ${ }^{6}$
}

Received: 7 July 2015/Revised: 18 March 2016/Accepted: 8 April 2016

(C) Springer-Verlag Berlin Heidelberg 2016

\begin{abstract}
Enterprise businesses are more than ever challenged by competitors that frequently refine and tailor their offers to clients. In this context, enterprise information systems (EIS) are especially important because: (1) they remain one of the last levers to increase the performance and competitiveness of the enterprise, (2) we operate in a business world where the product itself has reached a limit of performance and quality due to uniform capacity of industrial tools in a globalized economy and (3) the EIS can increase the product value thanks to additional digital services (built on data associated to the product) in order to meet and fit better client's needs. However, the use of EISs reaches a limit in collaborative environments because enterprises management methods diverge and EISs are mainly inflexible resource packages that are not built with an interoperability objective. Consequently, we need to make EISs interoperable in order to achieve the needed gains competitiveness and performance. This paper contribution can be summarized as follows: (1) it relates existing work and it examines barriers that, at the moment, are preventing further improvements due to current methodological and technological limits, and (2) it proposes a conceptual framework and five challenges that model based approaches must overcome to achieve interoperability between EIS in the near and long term.
\end{abstract}

Gregory Zacharewicz

gregory.zacharewicz@ims-bordeaux.fr

1 CNRS IMS, UMR 5218, University of Bordeaux, 33405 Talence, France

2 VMASC, Old Dominion University, 1030 University Boulevard, Suffolk, VA 23435, USA

3 Centre of Technology and Systems, CTS, UNINOVA, 2829-516 Caparica, Portugal

4 Hardis/Hardis Conseil, 3 rue Guglielmo Marconi, 44800 Saint Herblain, France

5 Harbin Institute of Technology, No. 92 West Dazhi Street, Nangang District, P.O. Box 315, Harbin 150001, Heilongjiang, China

6 Interop Vlab, Bureau Aquitaine Europe, 19 av. de l'Yser, 1040 Brussels, Belgium 
Keywords Enterprise information - Model-based interoperability · Model-driven engineering/architecture $\cdot$ Service systems $\cdot$ Simulation $\cdot$ Semantic approach $\cdot$ Social networks

\section{Introduction}

The differentiation with competitors in manufacturing domain will be more and more based on additional digital services. These services will be created by gathering and assembling information coming from value chain partners. One problem is that partners use different processes, organizations and different enterprise information systems (EIS); which leads to horizontal barriers of interoperability. Also, a recurrent issue in building EIS is the mismatch between the different views (models) where business representatives and end-users express their needs in terms of desired functions, in particular to represent the business and decision support process. On the other side the technical architect of the EIS deals with technical constraints relative to the EIS implementation. It leads to vertical barriers of interoperability. Enterprise modelling approaches have been identified to lower the risk of errors and non-interoperability if they are used from the beginning of the specification (Chen 2013).

Some works have been done in the last decades to increase the interoperability of EIS using standardized modelling approaches. Model-based interoperability relies on the use of a common language provided by the relatively unambiguous expressiveness of formal or semiformal models as the basis for making EIS's interoperable. However, these approaches are limited by the ability to transition between models and physical implementations of a solution. In order to overcome those limits in the European Union, the Future Internet Enterprise Systems (FInES) cluster has described a roadmap with some perspectives and objectives for the next generation of enterprises. In this article, we elaborate on those objectives with a special emphasis on the information system point of view. This paper presents existing model-based methods to build EIS and the barriers that prevent their full interoperability. The paper is organized as follows: Sect. 2 presents a short historical outline of the interoperability research. Section 3 discusses the current state of the art in building model-based EIS and points out the current barriers and challenges that prevent interoperability; Sect. 4 identifies challenges that have to be addressed for the Next Generation Enterprise Information System (Next Gen EIS) and it presents a short and long term objectives for the Next Gen EIS. The Sect. 5 is giving a conclusion.

\section{Enterprise interoperability historical review}

EIS interoperability is one of the main concerns of the Enterprise Interoperability (EI). The EI research roadmap, published by the European Commission in 2006, points to the need for more flexible Enterprise Information System (EIS) as an important research challenge. This flexibility is achieved, at least in part, by 
developing the "Interoperability" which is described as the ability of interaction between enterprise systems. The postulate is to say that interoperability is considered significant if the interactions can take place at least at three different levels: data, services and process, with a common semantic understanding (Chen et al. 2008). The methodology proposes guidelines to support modelling and connection capabilities between these levels.

The Levels of Information System Interoperability Model (LISI) project launched in 1993 by MITRE and the Working Group on C4ISR integration and the Working Group on CCA architecture (C4ISR 1998). LISI is a reference model and general framework to evaluate interoperability of IS. It is a methodology to identify, measure, evaluate and certify the necessary degree of interoperability reached or between organizations or systems.

Later, in 2004, the research Network of Excellence (NoE) INTEROP and ATHENA Integrated Project characterized and formalized Interoperability at different abstraction levels (Chen et al. 2008). In particular the definition of EI was explicitly provided in the frame of the INTEROP-NoE (I-VLAB 2007). In addition, the network has created a methodology to tackle interoperability problems through the identification of barriers preventing interoperability (Chen et al. 2008). During the past decade, consortiums from the successor of the NoE, the "Interop VLab" platform (I-VLAB 2007), have conducted projects to overcome some of the interoperability barriers by frequently referring to model-based approaches.

More recently, between 2010 and 2012, the Future Internet Enterprise Systems (FInES) cluster, supported by European Commission, has defined the EI as "the capacity that two or more enterprises, and their systems, have of cooperating over a period of time towards a common objective". It introduced the necessity of a common objective reached in a "seamless way" (FInES 2012). The ENSEMBLE project (Lampathaki et al. 2012) has worked to reach this interoperability objective and define a scientific baseline for interoperability research.

The interoperability concept is now extended to IT, organizations and physical means (Ducq et al. 2014). Some authors, for instance Xu and Wang (2011), have embedded interoperability inside the "service" paradigm. Here, the "service approach" uses indifferently, under a standardized approach, the different resources of the industrial domain. In the same vein, Gusmeroli (2008), one co-author of the FInES cluster report, stated that European research activities in FInES will now be pushed further to a next step: "the paradigm shift from Enterprise Interoperability to Service Driven Innovation". It means that information exchanged between the EIS components will be seen as a service request/supply. They rely on web services that will increasingly tend to uniform data exchange to facilitate interoperability.

We assume that the support of models that were previously designed to support for EI can be now specialized for EIS. Currently, the use of models-based approaches to support the interoperability of EIS remains mostly in the field of research projects and is not sufficiently implemented yet in industry. Consequently, model-based interoperability remains a challenge for Next Gen EIS. For instance, it is still a core consideration of EU Commission in the call for project "H2020 Future Internet" where cloud computing and internet of services are used to gather and handle heterogeneous information supported by model-based methodology. 


\section{Model-based approaches and barriers for enterprise information systems interoperability}

This section presents a state of the art on most used model-based interoperability approaches to improve EIS. Indeed, all major research initiatives agree that the problem of interoperability can be in part solved by the unambiguous descriptions (i.e. semi-formal or formal models) of the proposed EIS (Chen 2013). We identify and detail major model-based issues, discuss current solutions, approaches and frameworks and present relative barriers that EIS must overcome in order the implement Next Gen EIS.

Research on EIS engineering has claimed emerging models and tools at different abstraction level to describe an appropriate view of the EIS. Figure 1 presents a methodological description of the collaboration between two enterprises. Different abstraction levels are defined: Business, Process, Service and Data and Enterprise collaboration. These different abstraction and viewpoint levels require different models that involve different categories of information and do not match instinctively (NIST 2010). Figure 1 associates these objectives in a unified global view. It summarizes the contributions of this paper that consist in combining five models-based approaches to support significantly the design of Next Gen EIS. Each dimension is a challenge that will be described in the next subsections and assembled in the Next Gen EIS Conceptual Framework (Fig. 2) contributing to reach desired qualities of the future enterprise.

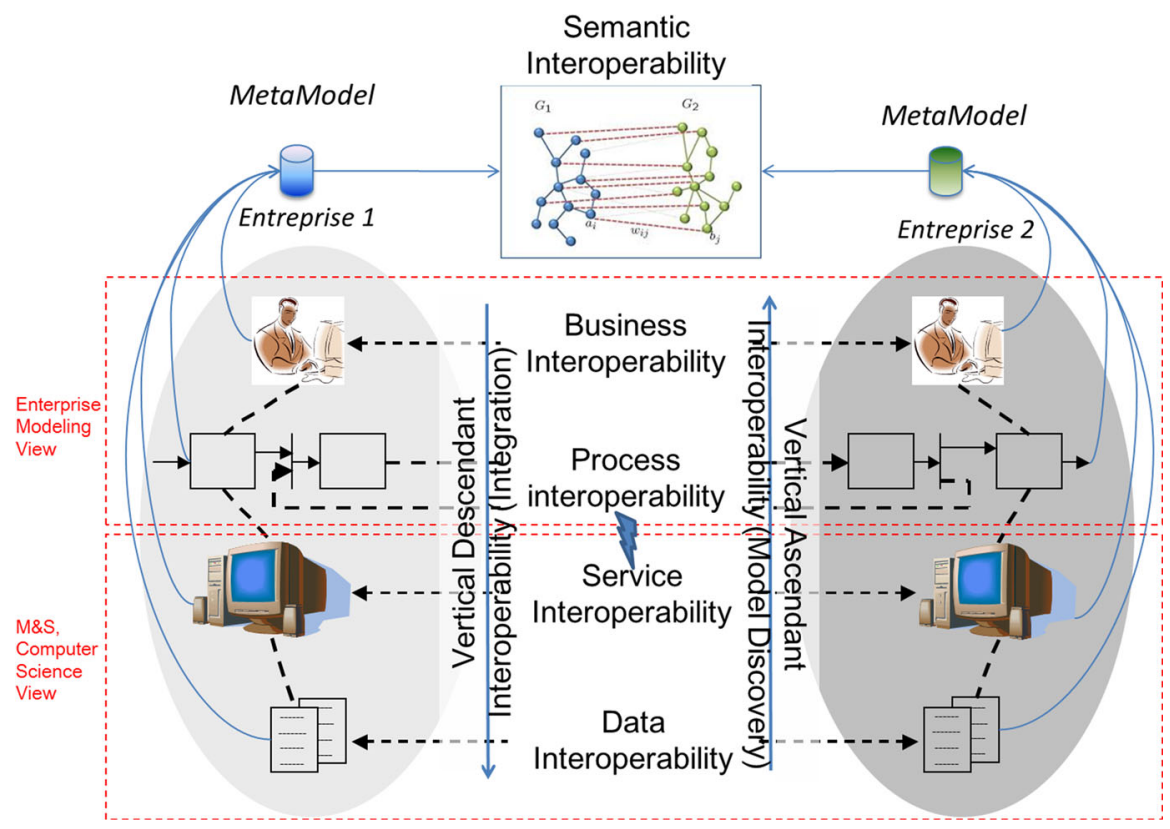

Fig. 1 Next Gen EIS major interoperability concerns and methodology 


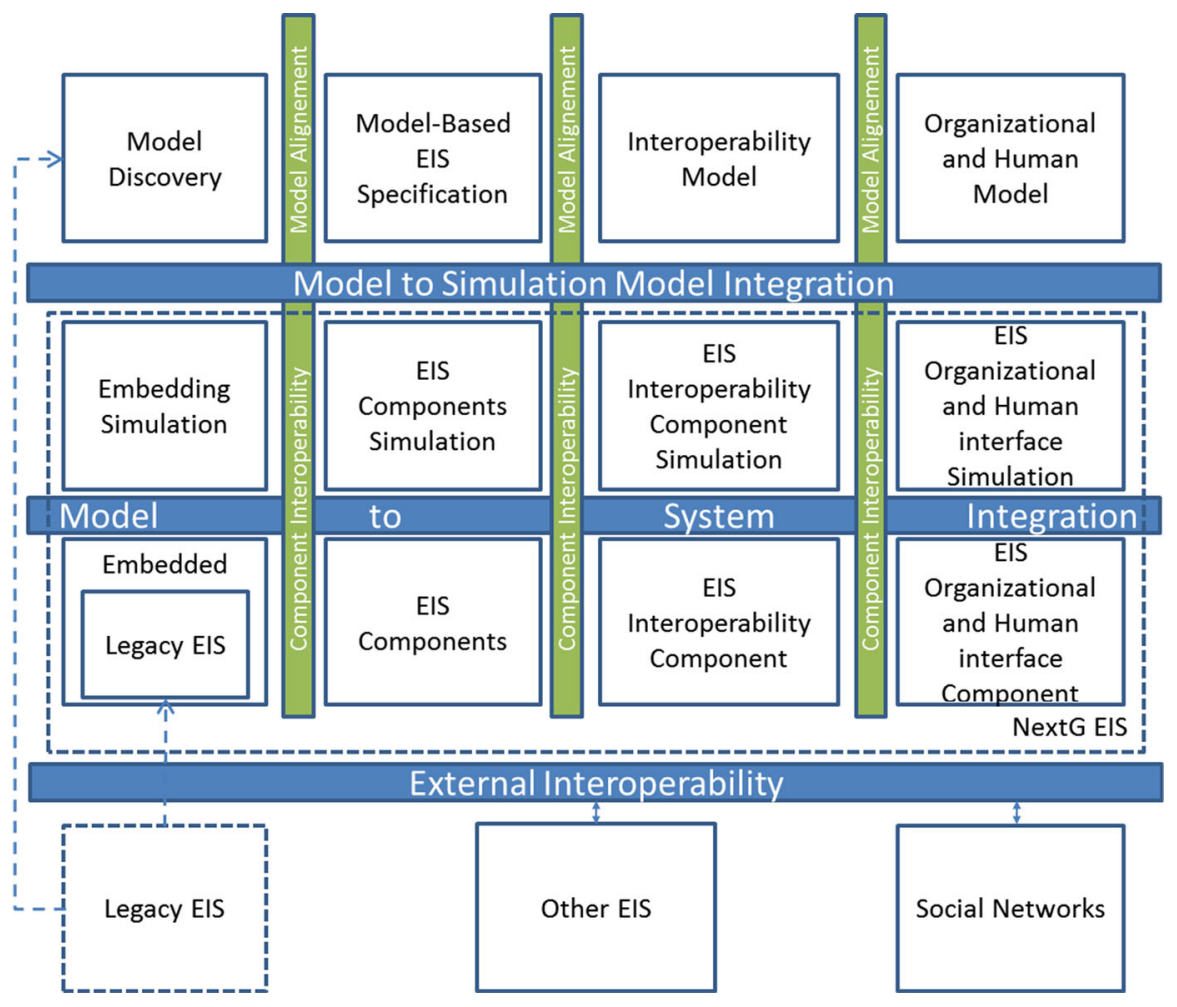

Fig. 2 Next Gen EIS model-based driven conceptual framework

Figure 1 assumes that the goal of interoperability of Next Gen EIS will be achieved through efficient model matchings to ensure both horizontal interoperability (between enterprises 1\&2, Fig. 1) and vertical interoperability model transformation to ensure interoperability between business people and the IT department (between enterprise levels noted with a thunder icon on Fig. 1).

These works about interoperability of the Next Gen EIS can be also considered, in a larger context, as a contribution to reach some of the desired general characteristics enounced in EU FInES roadmap for future enterprise (FInES 2012). This roadmap has defined vision and research objectives to exploit the full potential of the Future Internet in enterprise of 2025. It is followed by a community of more than 750 stakeholders. It has been the subject of more than 30 FP7 and FP6 projects and has permitted numerous high-quality publications. The roadmap addresses the future internet-based enterprises. The elaboration focused on 9 Qualities of Being (QB) that are considered strategic for the enterprises of the future, independently of the industrial sector, the size and the organizational model they will follow. We have selected among them 5 pertinent qualities for the enterprise information system that we recall below. 
I. Glocal enterprise is able to interpret the needs of different markets, scattered all over the planet, understanding the local specificities and constraints while maintaining an overall view of the opportunities.

II. Inventive enterprise is aimed at supporting continuous innovation, with an inherent willingness to develop creativity and skills in open and cooperative environments.

III. Agile enterprise is capable of quickly responding to the unceasing challenges of the market and to stimulate continuous improvement and innovation required by the global competition, by adopting new organizational models and new technological solutions.

IV. a. Humanistic enterprise is placing the person at the center, carefully considering needs and quality of life of the workers, customers, but also of social communities at large.

$I V$. b. Cognitive enterprise is capable to acquire, organize, and redistribute the enterprise knowledge, among different actors, permeating the whole organization, reaching the right actors with the right information in the right moment.

$V$. Sustainable enterprise is characterized by the ability to operate while adopting values and strategies that aim beyond the revenue, developing environmental awareness, social responsibility, without losing the capacity of producing wealth.

Each quality selected in FInES has been considered from the EIS point of view and has been listed in the first column of Table 1. In the second column, in front of

Table 1 Existing approaches and barriers to EIS

\begin{tabular}{|c|c|c|c|}
\hline $\begin{array}{l}\text { Future Internet- } \\
\text { based enterprise } \\
\text { wanted qualities } \\
\text { (FInES 2012) }\end{array}$ & $\begin{array}{l}\text { Existing solutions } \\
\text { for EIS }\end{array}$ & Interoperability barriers & $\begin{array}{l}\text { Next Gen EIS } \\
\text { challenges }\end{array}$ \\
\hline I. Glocal enterprise & $\begin{array}{l}\text { 3.1 Model } \\
\text { alignment: } \\
\text { ontology, DSL }\end{array}$ & $\begin{array}{l}\text { Reflect subjective point of } \\
\text { view, abstraction detail, not } \\
\text { adapted to different users } \\
\text { profiles, matching problems }\end{array}$ & $\begin{array}{l}\text { 4.1 Model alignment: } \\
\text { semantic information } \\
\text { layer, AHP, short } \\
\text { lived ontology }\end{array}$ \\
\hline $\begin{array}{l}\text { II. Inventive } \\
\text { enterprise }\end{array}$ & $\begin{array}{l}\text { 3.2 Model to system } \\
\text { integration: driven } \\
\text { approaches MDA, } \\
\text { MDE }\end{array}$ & $\begin{array}{l}\text { Non automatic, enrichment } \\
\text { required }\end{array}$ & $\begin{array}{l}\text { 4.2 Model to system } \\
\text { integration: MDSEA, } \\
\text { MDI }\end{array}$ \\
\hline III. Agile enterprise & $\begin{array}{l}\text { 3.3 Reverse } \\
\text { modeling: reverse } \\
\text { engineering }\end{array}$ & $\begin{array}{l}\text { Missing the behavior and the } \\
\text { dynamic aspect }\end{array}$ & $\begin{array}{l}\text { 4.3 Reverse modeling: } \\
\text { model discovery, } \\
\text { process mining }\end{array}$ \\
\hline $\begin{array}{l}\text { IV. Cognitive and } \\
\text { humanistic } \\
\text { enterprise }\end{array}$ & $\begin{array}{l}\text { 3.4 Organization } \\
\text { models alignment: } \\
\text { human in the loop, } \\
\text { ERP }\end{array}$ & $\begin{array}{l}\text { Wrong matching, domain } \\
\text { dependent, human and social } \\
\text { aspects not considered }\end{array}$ & $\begin{array}{l}\text { 4.4 Organization models } \\
\text { alignment: social } \\
\text { networks ontology }\end{array}$ \\
\hline $\begin{array}{l}\text { V. Sustainable and } \\
\text { sensing }\end{array}$ & $\begin{array}{l}\text { 3.5 Modeling } \\
\text { indicators: } \\
\text { building } \\
\text { indicators, } \\
\text { validation }\end{array}$ & $\begin{array}{l}\text { Converging on common } \\
\text { metrics, quantitative data } \\
\text { missing }\end{array}$ & $\begin{array}{l}\text { 4.5 Modeling indicators: } \\
\text { performance, } \\
\text { alignment, hybrid } \\
\text { simulation }\end{array}$ \\
\hline
\end{tabular}


each quality, we list current EIS solutions followed a list of interoperability barriers and a list of Next Gen challenges.

In the following Sect. 3; the current state of this domain is presented and barriers that prevent the full interoperability are identified. Then the Sect. 4 will present the future of these model based techniques.

\subsection{Model alignment}

From their origins, Enterprise Modelling Methods have been dedicated to systems engineering. They found mainly their origin in System Theory (Mesarovic and Takaraha 1975), for Math bases (Lemoigne 1977), for concepts, and Modelling and Simulation Theory (Zeigler et al. 2000) for experimental frame and behavior.

Frameworks gathering different models have been developed from the 80s such as Graphs with Results and Activities Inter-related (GRAI) framework (Chen et al. 1997) to represent decision and physical parts of systems. More recently, generic frameworks, such as Computer Integrated Manufacturing Open System Architecture (CIMOSA) (Kosanke 1995) or Generalized Enterprise Reference Architecture and Methodology (GERAM) (Ducq and Vallespir 2005) have composed and extended existing ones to specify enterprise systems. It is important to note that some initiatives proposing enterprise modeling frameworks, such as CIMOSA, support the enterprise "integration" of machines, computers and people rather than interoperability. However, a distinction needs to be made between integration and interoperability. Integration tackles strong connections between systems where interoperability is providing looser coupling. These frameworks define several modelling views with several kinds of the enterprise model (generic, partial, conceptual, structural realization, etc.). These cited works are proposing enterprise modeling frameworks, rather than formal models and are not developed with the objective to explicitly define all concepts and thus, to enable their interconnections and validation. It means that they do not define clearly the list of concepts included in the models and how to relate the different views of the same framework and how to go from macro to micro modelling detail. In addition, even if these frameworks can be applied in the frame of enterprise modelling for system engineering, they cannot be considered as dedicated approaches for a domain specific uses. They stay at enterprises conceptual level definition. The connection, assembly or merging of these models in the objective of EIS interoperability (Fig. 1, horizontal interoperability) still relies on frequent misunderstanding, shortcomings and models errors that lead to develop unsuitable EIS.

To overcome that interoperability limitation, several initiatives have been launched. For instance, NIST with Model Based enterprise is working on the merging of different models to facilitate manufacturing process implementation with Model Based Enterprise (MBE) (NIST 2014). Also, given their wide industrial acceptance, Enterprise models are excellent starting points for making formal languages, namely Domain Specific Languages (DSL). DSL can be viewed as a formalized way to manage ubiquity between different local views responding to need on future enterprise "Glocal" objective. As the demand for collaboration among enterprises keep increasing, EIS interoperability is pursued continuously in 
order to enable better understanding and matching of data exchanged between partners' heterogeneous EIS. For conceptual and technical consideration, semantic heterogeneity is becoming a major barrier that obstructs achievement of EIS interoperability. Borst (1997) identified that sharing and reuse of ontologies across different domains and applications can therefore improve information systems design. To address semantic interoperability in EIS, ontology-based approaches are widely applied due to the rapid development of semantic web related technologies and the benefits that it brings to facilitate semantic interoperability (Fig. 1, semantic interoperability matchings). One of the objectives of the semantic matching based approaches is to reconcile the concepts as described by Giunchiglia et al. (2009) in a statement paper. Most of the current ontology (matching) approaches (Shvaiko and Euzenat 2013) seek correspondences from lexical level and structural level rather than from semantic level directly. For instance, several approaches have proposed to bridge federated EIS data thanks to ontology alignment that seeks semantic correspondences between different EIS. With the objective to develop enterprise data interoperability at a semantic level, several works (Panetto and Molina 2008) focused on adopting ontology alignment techniques to contribute to a federated EIS interoperability approach. The difficulties are caused by the diversity and ambiguity of natural languages, which are used to represent the entities in ontology.

Several works have proposed word-based ontology alignment approaches by applying the knowledge from Natural Language Processing (NLP) and Information Extraction (IE) with the data of the EISs to reconcile. The recognition process of "core words" is performed based on pre-defined rules and part of speech (POS) of words. Besides the core word-based method for ontology alignment, to handle diverse situations and enhance matching ability, matchers at lexical level and structural level are frequently applied by reusing algorithms such as edit distance, $\mathrm{n}$-gram and similarity flooding. Also, in simulation domain some approaches (Tolk et al. 2006) have been developed to drive the interoperability by the ontology. They have reused the OWL language as media to bridge the interoperability.

Nevertheless, the complete semantic-based mechanism using ontology alignment gathered directly from EIS with a full ontology-driven architecture querying data from multiple databases is still claimed for more than just one prototype. This architecture shows certain extendibility to be proposed in the future but still need to be customized to be applied to several application scenarios according to specific demands. For instance Pietsch et al. (2014) recently compared a group of general matching problems. This state-of-the-art comparison algorithms reported low quality results. The problem is that algorithms from off-the-shelf products are designed for typical use cases and for particular model types such as class diagrams or similar model types only.

\subsection{Model to system integration}

New concepts, ideas and proposition, coming from enterprise requirements, have to be rapidly integrated into the EIS as required in the inventive quality of future Internet based enterprises. A major problem frequently identified in the EIS definition is the gap between different people visions (models) that describe and use 
the information process (Fig. 1, vertical descendant interoperability). Kleppe et al. (2003) early identified the interest to link the different visions through models. The process can be either defined for creating physical product or services. It opposes on one side the business view and on the other side the technical one. Some efforts have been produced to reduce this gap, for instance model-based reconciliation can be considered as an issue. Several model driven methods have emerged to support the model transformation and at the end to facilitate the trans-level interoperability. The first and most used one is the Model Driven Architecture (MDA) developed by OMG (2010); it is frequently implemented on different UML models. MDA is a system design approach for the development of software systems. It provides a set of guidelines for the structuring the specifications, which are expressed as models. MDA is one standardized support for model-driven engineering (MDE) of systems. Its use for IT system development based on service implementation is important in industrial and research domains.

In Asia, approaches such as Value-Aware Service Engineering Methodology (VASEM) defined by Harbin Institute of Technology (Xu and Wang 2008) tries to relate the service model space with the value model space with expressing at each modelling level the customer value expectation for the services of the information system. Also, Zhu et al. (2004) shows Model Blue, a set of model-driven business integration and management methods, frameworks, supporting tools, and a runtime environment, developed by the IBM China Research Laboratory (CRL). In this work, model-driven technologies were utilized for addressing challenges of BPIM such as fast and efficient development, reusable and robust framework, and software solutions easy to be revised and executed. Wang et al. (2008) proposed a metamodeling framework for unified requirement called Role-Goal-Process-Service (RGPS) as a common basis for domain modeling, requirements elicitation and analysis, and other phases in the lifecycle of networked information systems, and by model-driven approaches, design specification and web service-based software solution can be generated from the RGPS models easily. O-RPGS (Sun et al. 2010) is an extension of RGPS for the domain modeling in service-oriented software development, in which process models can be automatically generated from highlevel business goal levels. Further, On-Demand Service-Oriented Model Driven Architecture (ODSOMDA) (Zhang et al. 2012) adds more SOA elements into MDA to realize the model transformation for the rapid development of Software as a Service (SaaS) and Enterprise Mashup Applications. Considering the design and development of high complex System of Systems (SoS), Hu et al. (2014) presented a Model Driven approach for service oriented SoS architecting, modeling and simulation, providing multi-level models, model transformations and service implementation artifacts generation to facilitate the alignment between high-level complex business requirement and IT systems.

In USA, Another approach has been proposed in Arsanjani et al. (2008), which describes a service-oriented system development method to transform businesslevel requirements gradually into an SOA-based service system. In addition, the works presented in the paper of Anaby-Tavor et al. (2008) presented a model driven process as the core of a service engineering method. 
Others have adapted Model Driven (MD) to interoperability, such as Model Driven Interoperability (MDI) methodology that was realized in the frame of the Task Group 2 (TG2) of INTEROP-NoE (Bourey et al. 2007). They propose to define an approach, inspired from MDA. The goal is to tackle the interoperability problem at each abstraction level defined in MDA and to use model transformation techniques to link vertically the different levels of abstraction and horizontally to ensure interoperability of models of collaborating enterprises at each level. The main goal of this methodology is to allow a complete follow-up from expressing EIS interoperability requirements to solution coding. Yet, MDI was majorly focused on Information Technology (IT) systems not considering much the human organization and physical means resources.

Nevertheless the development is mainly IT directed and the models are already designed with this IT goal, not always centralizing the users view and requirements. Moreover, most of the MD approaches presented do not propose and support specific modelling languages. Another drawback is that model transformation remains limited to certain categories of models as presented by Den Haan (2008). Also, the modeler is not guided to delimit the subpart of the EIS to be computerized. Silingas (2013) stated that a tool to identify and delimitate the subpart of the model to be considered at a down level modelling would be valuable to prepare transformation. In addition, the transformation is not fully automatic; the model generated from model transformation is typically an abstract structure with slight content coming from the information collected in the source model. The transformation to lower level models requires systematic user enrichment.

\subsection{Reverse modelling}

The implementation of an EIS is always done in connection with other existing software and hardware components. It means that most of the models are starting from legacy systems; another challenge is in consequence the reusability aspect. Reverse engineering work was frequently included in model specification methods. This work was done by the modeler in charge to observe the system to model. Now the observation of the existing system is assumed to be assisted by tools, it is known as model discovery. It should allow to guide and to limit the reorganization of the EIS, using a bottom up approach in an upstream step of the top down approach described previously (Fig. 1, vertical ascendant interoperability). It can be investigated for instance using Architecture Driven Modernization (ADM) (OMG 2013) to discover the code data structure and function. In Davenport (2013), the authors insist on the interest to reuse existing parts of EIS in the innovation process. The challenge is to reuse as much as possible the valid data structure, functions and behavior from existing system to be sooner ready to use and, above all, flexible enough to be rapidly modified according to modifications in the enterprise strategy.

In computer science, Jouault et al. (2008) introduced MoDisco tool that supports IT modernization projects. It is intended to support systems redevelopments that cope with legacy systems in a less tedious and time consuming task. The very first step of the model discovery process in MoDisco is to define the meta-model corresponding to the models elaborated. Then, the second step is about creating one 
or many discoverers. These discoverers extract necessary information from the system in order to build a model conforming to the previously defined meta-model. The way to create these discoverers is often manual but can also be semi-automatic. This approach is mainly implemented using an Atlas Transformation Language (ATL) model-to-model transformation (Bézivin et al. 2005) taking as input a Knowledge Discovery Model (KDM), conforming to a meta-model and producing as output a model conforming to the KDM models into a UML meta-model. After the conversion, UML models are generated. These converted UML models include Packages, Interfaces, Classes, and also the properties, operations of classes, associations and dependencies among classes. For instance, Tu et al. (2014) have proposed a methodology for model reversal in the domain of EIS. This methodology has been based on MoDisco linked with other Model Driven approaches (ADM, MDI, HLA FEDEP). It works at quickly developing adapters to integrate legacy EIS components in distributed simulation based EIS.

Nevertheless the completely automated models discovery for existing systems is not reached yet and remains an open issue. This is mainly due to the fact that no approach is able to tackle properly all the different point of view (i.e. different models) required to describe the explored system. The model thus generated remains only a high level view of the problem, mainly limited to data structure and, in the best case, functional views. Another problem is the dynamic of the system that is still difficult to capture so it missed a clear behavioral model. For instance all the time related information (e.g. time life of the internal states, hidden internal functions, arrival times of input information, lead time to emit output information, etc.) is difficult to obtain and even at least difficult to estimate. It makes the models missing this information and so the implementation ambiguous regarding the temporal aspect.

\subsection{EIS and human resources models alignment}

There is for a long time a persistent requirement in the EIS domain that consists to combine properly organization structure and human resources with EIS (Fox et al. 1996). Ajaefobi and Weston (2005) stated that custom and practice in enterprise modelling are based on the specification, construction, operation and development of multiple human and technical systems so that they must be able to represent the human to be integrated in the EIS, for instance in an Enterprise Resource Planning (ERP). The model of interoperability between system and human can play a role to facilitate the access to the EIS for the users but also by anticipating their needs to display personalized interfaces. All enterprise modeling techniques developed still fail to integrate properly the human in the loop. Ajaefobi and Weston (2005) suggested ways of characterizing the skills and capabilities of human resources, with reference to strategic, tactical and operational business processes. In addition, they explain how these "models" of human resources can be deployed in the broader context of the modeling business to match the capabilities and behavior of stereotyped human systems to the specific requirements of business processes.

However, the modeling of human behavior techniques is generally known to give insufficient enough support for the information systems definition (Bouanan et al. 
2015). So, the human resource management is still the weak point of EIS because the human behavior is not sufficiently investigated and anticipated. Also the impact of the information exchange in the social networks (electronic or not) is more than frequently ignored in the data flow of the EIS.

\subsection{Modeling indicators for validation}

The EIS validity and capabilities to interoperate should match the objectives expressed by the enterprise business responsible. The issue consists in deciding how to transform qualitative requirements into appropriate quantifiable information and to control their consistency. The process starts by identifying the needs and then by being aware of sustainable objectives as a quality of Next Gen EIS. These conceptual objectives should be transposed, stated and enriched into quantified indicators using Model Transformation (see Sects. 3.2, 4.2). The evaluation of EIS interoperability from strategic to operational levels is still to be integrated in the development lifecycle. An idea proposed by the Model Driven Interoperability (MDI) (Bourey et al. 2007) approach is to identify the interoperability questions from the conceptual description of an EIS and to go down with it to implementation. The main question goes again in this framework with how to relate business objectives with EIS technical activity monitoring. It can be assumed that if the business objectives can be quantified (including the desired interoperability of the EIS), they can be used as indicators and be tracked over time. Here, a simulation can run the behavior of the EIS by integrating these indicators. It would allow modelers to verify the reachability of objectives given the capacity of the enterprise resources. It leads to test and validate part of the system behavior and can be anticipated progressively by simulation, allowing then more confident system integration as demanded in Jardim-Goncalves et al. (2012).

In general, all languages and models transformation are in search of the relevant indicators to be implemented in the simulation model in order to evaluate the results regarding defined objectives. Based on the proposed approaches described in the previous sections, some experiments have been carried out to define indicators commonly accepted. Also, some prototype tools have been implemented for evaluation and further application to support the design of Next Gen EIS.

E.g. Song et al. (2013) proposed an ontological based approach using the reference Ontology Alignment Evaluation Initiative (OAEI) benchmarking datasets to relate indicators. It compares OEAI with other approaches but no global and explicit metrics have been proposed. Some other work contributes to makes model transformations become more trustable thanks to simulation. Zhu et al. (2013) proposed a MDA-based trustworthy software development framework. During the transformation from CIM to PIM and from PIM to PSM, Petri Net and temporal logic are utilized to formally analyzing performance and checking correctness of software models, thereby enhancing the trustworthy of the final software code generated by MDA. Ko and Song (2012) proposed a model transformation verification approach enabling the semantics equivalence verification of the target model and the source model, by graph comparison algorithm and mapping patterns. Li et al. (2012) presented a validation approach for semantic consistency and 
correctness of model transformation in MDA using "transformation patterns". Considering that there are some properties that should be preserved before and after the model transformation, Li et al. (2013) further worked on defining and validating property preservation constraints for model transformation using Web Ontology Language (OWL) and description logic and validating the constraints through inductive logic.

Nevertheless, for both ontology, model transformation, language and models there is still a need to compare, align and rank results. In effect, even if research works and standardization initiatives have recently emerged (Chen 2013), there are no common metrics (or indicators) that can be fully admitted and used to compare if the level of interoperability obtained in the operational solution is coherent with the interoperability prescribed in the strategic model. Also, the choice and the quantification of the indicators are still challenging.

The current state of the art in the domain shows that the domain is very active and the proposed approaches start obtaining promising results but they still fail to be fully scalable and ready to be perfectly aligned to expected industrial EIS needs. The next section presents short, medium and long term goals for each of the areas discussed in this paper.

\section{Ongoing challenges for model-based interoperability of Next Gen EIS}

According to current state in the domain presented in Sect. 3, the postulate consists of saying that a system (e.g. an EIS) cannot be described with only one unique model. Several views have to be combined to have an, as complete as possible, understanding of it. This section discusses the recent advances, vision gaps, and future model-based solutions in each of the grand challenge identified in the Table 1 to fill the short, medium-term gaps towards Next Gen EIS.

This idea of creating a global toolbox for enterprise modelling as the one existing with UML in software design has been initiated in UEML (Roque et al. 2006). Some other tentative have been carried out to merge several frameworks in a unique one, such as GERAM that has been mentioned in Sect. 2. The main drawback of these frameworks is their limited use due in part to the size of the community and their complexity which can appear as a barrier to apply it in the real world during enterprise modelling sessions in the frame of systems engineering and consultancy. Other works have been proposed to combine modeling views, e.g. MDSEA (Sect. 4.2) and VASEM (Wang and Xu 2012), to describe and deploy the customer value at the same time that business requirements are transformed into technical specifications. It tries to respond to the service description demands that are growing nearly anarchically in the enterprise world with underlying concepts not explicited due to the lack of maturity of the domain. The cited frameworks do not fully consider the modular assembly/disassembly of components approach which is however now a core demand of the service approach. Also the reuse of the legacy and the human interaction is not frequently considered in the design of system. As a conclusion, up to now, no approach combines those different considerations. 
The general conceptual framework proposed in this work will contribute to pave the way with a Model-Based approach from legacy to new system. It starts from the exploration, understanding and discovery of existing models. E.g. Souba (2011) stated that discovering, the act of conducting research, are experiences that entail "languaging" the unknown. In building the EIS, the first objective is building a bridging language between the harmonizing visions of the EIS, it is not addressed yet, and it has to be discovered for joining divergent visions with interoperability. Another main challenge is to deploy coherently the models according to different users' (business people, customers') values and needs at each modelling level. The communication (as interoperability or integration) is a common ground or interface to establish a dialog between entities. The proposition coming in the next subsections will show common ground for this conceptual framework that can be built on metamodel or super model that is a model of a model. Metamodeling is the process of generating such metamodels. Indeed, metamodeling alignment is also a "languaging" process. This is the only way to obtain at the same time an EIS aligned with the enterprise strategy but also aligned with the customer and users expectations, keeping in mind that most of the EIS project failures are coming from a lack of appropriation from the users.

Nevertheless the postulate to bridge interoperability by using a common language can be understood paradoxically going in an opposite way regarding prospective views of interoperability that prefigured a "federated interoperability". Federate means that interoperability has to happen on the fly without common persistent Meta description (Chen et al. 2008). To meet both of these objectives, the proposition keep considering the need of models and meta-modelling level but the novelty is that the meta-level can be non-persistent (short-lived) and just used in order to identify the respective concepts to match and to facilitate the model transformation. On the top of these, metamodels are, in recent applications, more and more structured and defined according to a common meta-meta language. At the end, according to Sect. 3.5, a remaining question is, in the future, the place of the human in the loop, including the part of social networks in the Next Gen EIS.

Based on this discussion, it emerged the need to rationalize these new approaches in a conceptual framework. We based it on the methodology introduced in Fig. 1 and MDA in order to sustain connection, combination and orchestration of EIS components (including services). The article describes this new conceptual framework that gathers all the recent needs of the Next Gen EIS specification and development in Fig. 2. The Next Gen EIS Conceptual Framework is a two dimension representation. It proposes to consider interoperability between models first (Fig. 2, upper part and vertical bars). Here the model alignment (Sect. 4.1) can contribute. Then the models are transformed thanks to model to system integration into simulation models. The reason is the model is simulated before its final implementation to observe and validate desired properties (Sect. 4.2 and Fig. 2, middle part and horizontal bars). Then the final EIS components are implemented (Sect. 4.5 and Fig. 2, lower part). It shows 2 steps model integration (Model to Simulation to System) (Sect. 4.2 and Fig. 2, vertical path). The Fig. 2 bottom left identifies legacy systems for which two options are proposed: model discovery or 
encapsulation into adapters (Sect. 4.3). Finally, at the bottom right of Fig. 2, the connection with social networks is considered.

At the end, this Conceptual Framework is proposing a structural frame for Next Gen EIS. To go further, the development of tools to design models of services and EIS components will be determinant for the adoption by the user and the promotion of the Model-Based Driven Next Gen EIS Conceptual Framework. These tools will be the operational support to the business user to allow scalable modeling of concrete EIS use situations in order to design the scalable future Next Gen EIS. Some initiatives, such as the Service Life Management (SLM)ToolBox (MSEE 2014), have already emerged. This article presents in the following the detail of the contributions that the authors think they will be determinant support to this objective.

\subsection{Model alignment in Next Gen EIS}

Since the 90s (Wiederhold 1992), several efforts have been done to solve the concepts and data structure mismatch faced when interconnecting EIS in the form of a System of Systems (SoS). Nevertheless it remains a major interoperability barrier (Chen et al. 2008). As described previously in Sect. 3.1, the semantic approaches can help reunite the concepts. Research starts to cross this barrier thanks to recent semantic data (or concepts) matchers approaches but it is only the premise of an automatic language translation.

The matchers are combining lexical, semantic and sentence structure technics and rules. Several research tracks and questions are ongoing or considered as open issues for future research in this domain (Euzenat and Shvaiko 2007). Currently most of the defined rules are either designed to general purpose and are less efficient for specific work domain vocabulary and vice versa. For instance, the rules for core word recognition, in order to adapt to a specific knowledge domain, can be extended in future research; such as defining sets of specific rules. Most advanced approaches in matcher combination or aggregation has drawn much research attention, they focus mainly on multiple matchers applied to perform most efficient ontology alignment.

Although many multi-strategy based methods have been proposed, more customizable and dynamic methods are still expected in order to improve the combined matching results. E.g., recent works presented in Song et al. (2013) have proposed to use Analytic Hierarchy Process (AHP) to customize ontology alignment for more accurate matcher aggregation. AHP has been previously used for weighting computation in certain fields, such as e-learning and marketing. This is an analytic approach based on AHP that has been used and applied to learn the weights of each matcher. This method aims to automate the aggregation process and to improve the combined matching results in order to support EIS architect in a digest effort. Nevertheless, the lexical matcher performs an alignment task mainly based on the labels of entities coming from databases or programming object labels at the moment. If the comments, specific to a domain and additional annotations of the entity were also taken into account as semantic sources to assist the alignment, the results could be improved. 
The general process of (Song et al. 2013) has been reused and extended for the purpose of EIS interoperability in Fig. 3. Concerning the solution to build Semantic Information Layer (SIL) for developing data interoperability, the rules for extracting ontology from relational databases are mainly defined at schema-level. More rules regarding instance-level for extracting records in Relational Data Base (RDB) to ontology instances can be extended in order to enrich the semantics of data. In consequence, the first step of this work (Fig. 3 1) is related with emergent big data approaches to manage the pre-process of relevant data by handling them from the full content of the distributed EIS data base. In this approach, the multi matcher aggregation method is being used according to domain based strategies (Fig. 32 , $2^{\prime}$ ). Several similarity indicators can be used to automate the assignment of scales in applying the multi criteria approach AHP (Fig. 3 3, 3'). In order to apply this proposed weighting method in other fields, the way to calculate the similarity indicators can be adapted accordingly, such as based on certain parameters that reflect best the importance of alternatives in the domain. Another future work is the operationalization of a non-persistent ontology (Zacharewicz et al. 2009), with a relatively short lifetime. From that postulate they introduced the concept of "short lived ontology". This ontology can be, in some cases, suppressed after use or can have finite duration validity (Fig. 34 , end of the process). This "short-lived ontology" approach is not fully implemented and used in large systems, since it faced the problem to handle and retrieve information within a huge volume of data frequently updated (i.e. the big data). It will be used to dynamically handle the data interoperability issued from big data to address enterprise fixed-term collaboration situations.

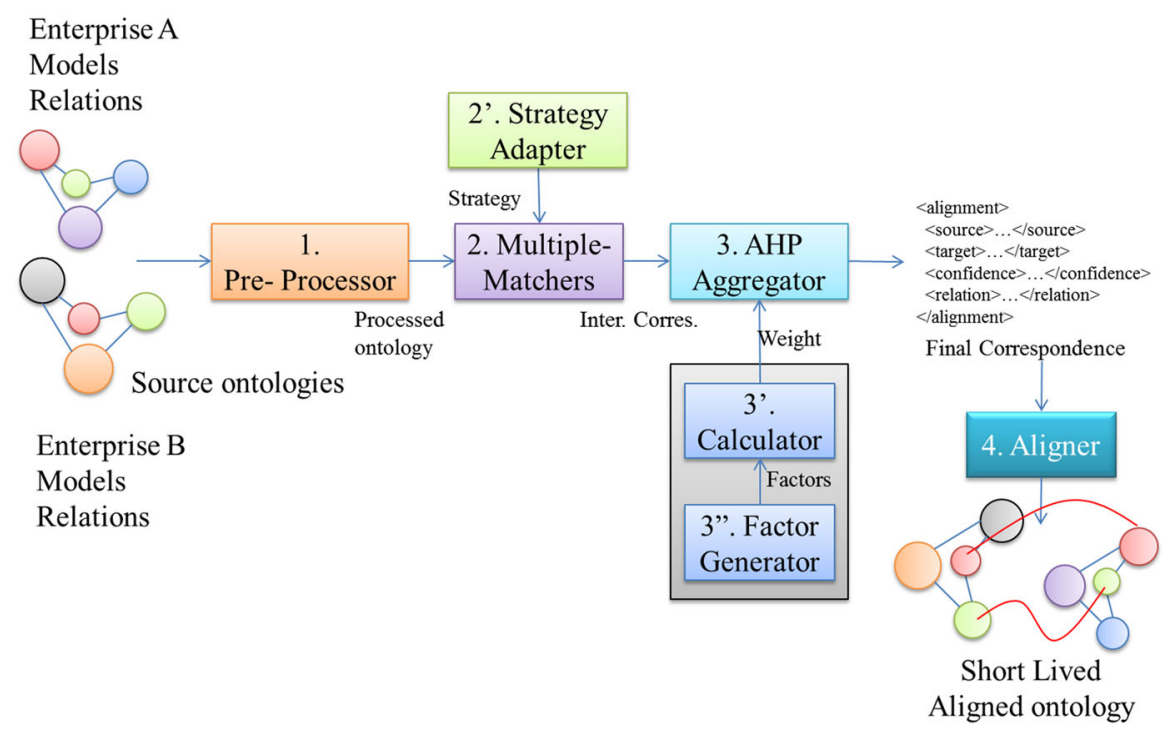

Fig. 3 Multiple strategies-based ontology alignment. (Adapted from Song et al. 2013) 


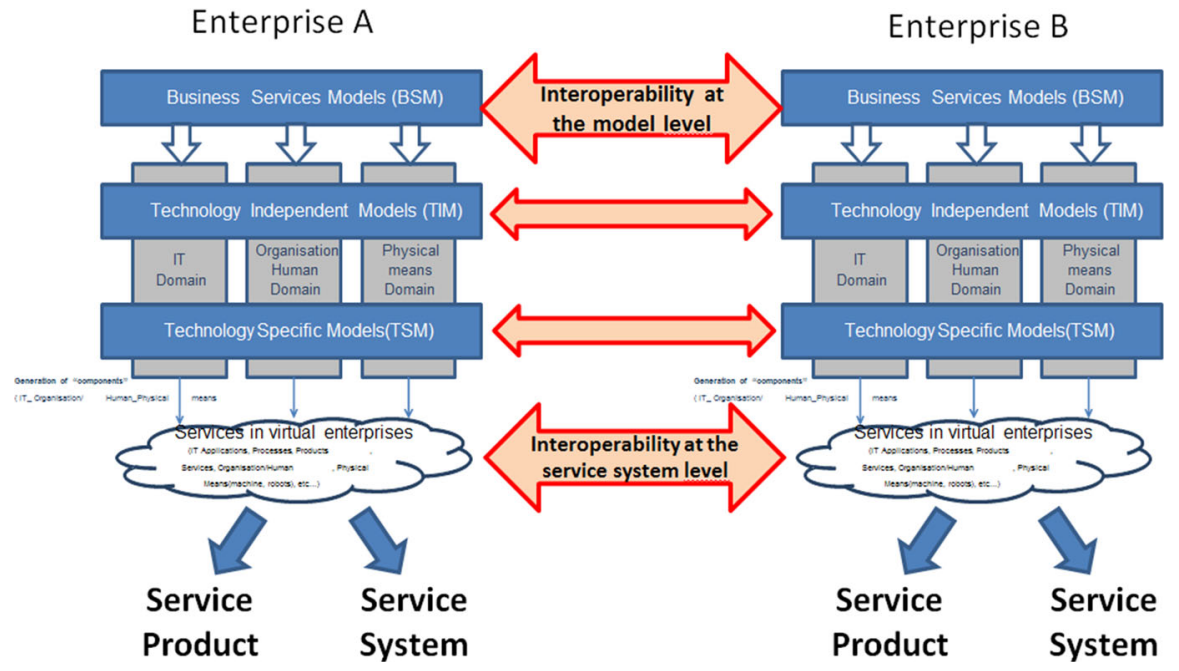

Fig. 4 MDSEA methodology

Lastly, considering the semantic interoperability needs at conceptual level in enterprises, an extensional ongoing work, which proposes to apply ontology alignment for developing the interoperability between MDA and simulation models, is being carried out based on the proposed ontology alignment approaches (Fig. 2, vertical alignment) (Song et al. 2013). Remaining work mainly concerns elaborating the detailed method and giving operational application steps, the works includes: (1) the rules and formalisms of information exchange, and (2) the way of exchanging information between the two sides using ontology alignment. These objectives can be reached within a middle term horizon.

\subsection{Model to system integration in Next Gen EIS}

The different visions of the business process between the enterprise leaders and the developers are still a gap. Some barriers persist between these two views of the EIS to implement. Thoroughly, one major barrier in EIS interoperability is the matching between the concepts announced in the enterprise models of services by the business responsible and the technical services implemented.

The Model Driven Service Engineering Architecture (MDSEA) is inspired from MDA/MDI. This methodology is proposed in the frame of the MSEE project (Ducq et al. 2014) that defines its first Grand Challenge as making SSME (Service Science, Management and Engineering) evolving towards Manufacturing Systems and Factories of the Future. MDSEA provides an integrated methodology dealing with modelling languages at the various levels of abstraction to support service models and service system design and implementation (Fig. 4). The relationship between the MDSEA modeling levels (Business Specific Model (BSM), Technical Independent Model (TIM), and Technical Specific Model (TSM)) and the Service System 
lifecycle phases (user-requirements, design and implementation) is defined, and one of the most important innovations is the integration between domain components (IT, Organization/Human and Physical Means) at the BSM level, ensuring that these integration aspects will be spread out at the other architecture levels. In this sense, MDSEA is considered as an adaptation of MDA/MDI approaches to the engineering context of services in the virtual enterprise environment.

On the IT side, several works have been proposed to give guidelines for service definition and implementation. The authors Camarinha-Matos et al. (2013) introduced the notion of "Transparent inter-enterprise plug-and-play infrastructure". They proposed the ARCON reference methodology framework that distinguishes different modelling steps from business to IT. The authors Lin et al. (2009) introduced the concept of Service Driven Architecture (SDA). This approach is more dedicated to the implementation of SOA considering mostly the technical constraints at the implementation step. Also, an engineering viewpoint has been described by Wang et al. (2010) in order to propose a service value meta-model.

Then Bazoun et al. (2013) have recently proposed a first implementation of the MDSEA methodology from BSM to TIM in the frame of an open source tool. In detail, as part of the MSEE project and in the frame of the MDSEA approach, a collaboration of researchers and industrial professionals have delivered a tool to support model transformation from conceptual level of EIS description down to technical level. The result is the SLMToolBox that is an Eclipse Rich Client Platform (RCP) that allows transforming conceptual models coming from business level to BPMN (Bazoun et al. 2013). A second contribution is being done by transforming BPMN concepts into executable workflow going from BPMN 2.0 Diagram to one Workflow Engine Orchestration. To simulate the behavior of the BPMN model, the SLMToolBox transforms BPMN models into DEVS models (Zacharewicz et al. 2010). It runs the conceptual models on the non-existing enterprise services to test and verify the global behavior of the system, with existing enterprise services. Industrial partners of MSEE including Indesit, Phillips and Bivolino have recently used and adopted the tool for modelling service process. They concluded that it prepares finely the implementation by simulating the behavior to track performance indicators such as time and cost. However it does not achieve to reach the automatic development of TSM level EIS components at the moment.

Also, a general problem is to deal with hybrid situation where existing EIS components have to communicate with non-existing or unavailable yet services in the enterprise. The works proposed in Ribault and Zacharewicz (2013) have distinguished existing components to be reused and the ones to develop, using the SMLToolbox. Then they proposed to transform conceptual models designed with the tool to BPMN and BPMN to Discrete EVent Specification (DEVS). The DEVS models are used to mimic the behavior of enterprise future components with an interoperability link to the existing components through a High Level Architecture (HLA) Run Time Infrastructure (RTI). A Workflow Engine Orchestration was completing the interoperability with the RTI. The authors described a perspective to generate by model transformation a connector between the DEVS simulator and a workflow engine to solve the interoperability problem. The future scientific 
contributions will aim to transform BPMN to a workflow model of services, all embedded into the SMLToolBox, within a short term period. Another idea is to reuse the simulation feedback, i.e. as an automatic enrichment of services models from simulation results and failures.

As a conclusion, the model transformation is generating the abstract model from a higher description; but such a generated model always misses the semantic and technical details enrichment required each time going deeper and lower to an executable model.

\subsection{Reverse modeling to reuse system in models in Next Gen EIS}

The new system can gain in reusing or integrating at most the legacy parts. Davenport (2013) expressed the need to have a progressive improvement. The consequence is the necessity to make cohabiting old and new EIS parts. Here, rediscovering old practice and data, and reusing them is all about. Data structure and function is quite well proposed in reverse engineering tools. But when dealing with legacy EIS it is less evident capturing the behavior of the existing system. With the state diagram discovery, we can expect to start understanding the behavior of the existing system in order to combine more easily the new system with the existing environment. In this domain, OMG has initiated since 2003 the ADM initiative (OMG 2003).

In more detail, the reverse modelling can cover different aspects (view or model) of the system. Tu et al. (2014) has presented works to discover the structure and functions of existing EIS. The discovery of the EIS without meaningful internal behavior detail of the existing EIS is difficult. It can appear almost impossible to discover the full behavior, which supposes to solicit the existing EIS with all possible permutations of input and to identify outputs to deduce the internal states. If the model is used for describing the system logic with a general description, i.e. the key I/O relations, then a basic functional model can be sufficiently qualified.

If a behavioral view is required for process interoperability or business interoperability, structural and functional models are not expressive enough for displaying business behavior timed and causal details. In that case, the event log must be transformed into models that can formalize the detailed business logic, such as state-transition or DEVS model, that take into account the time. The causality needs to be carefully respected following a detailed timed dialog description between the process, the actors involved and the environment of the system. Some works have been the foundation to behavior model generation (Leue et al. 1998); they attempted transforming a reduced directed graph of the system execution paths into a state diagram. The program starts from an entry point of a directed graph and rebuilt the system execution paths. Then, Process Mining (PM) and Business Process Discovery have been proposed by (Van Der Aalst 2011) to operationalize the methodology. PM techniques allow for extracting information from event logs. For example, the audit traces of an EIS workflow process or the operation logs (Fig. 5, event log cylinder) of an ERP system can be used to discover models describing processes, organizations, and products. It produces transition systems or Petri Nets models. 


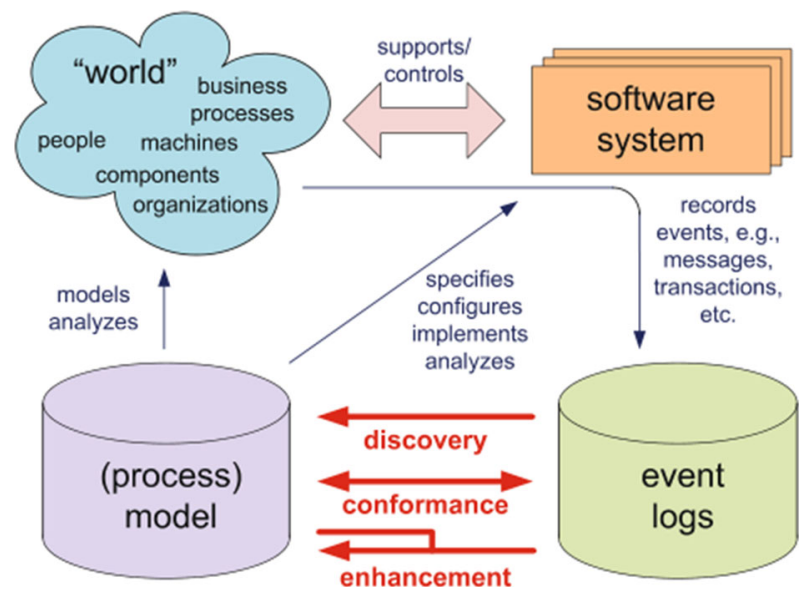

Fig. 5 Process mining. (From Van Der Aalst 2011)

This method has been reused as basis of works proposed in Wang et al. (2015). The authors have proposed to generate DEVS model of EIS processes from event logs (Fig. 5, process model cylinder) to gain from the use of the state life times and timed events. They have obtained results in terms of process models of EIS with valid sequences. But, the state life times of a process needs to be tackled using timed information that does not systematically exist in the event log. Rather than a deterministic value the proposition of the authors is to use the notion of time interval to adjust with uncertainty.

However, this approach is still ongoing and has not been fully validated. It can be considered as a promising perspective for Next Gen EIS. Also, the existing algorithm is only capturing a high level state description of the behavior. In short term perspective, the effort of this research will focus on getting the theoretical validation and improve the algorithm; by using for instance genetic algorithm that can auto improve their capacity to discover the behavior. Then the complete implementation will need a development that can be envisaged in the farther future.

Another approach from Colomo-Palacios et al. (2008) presents an architecture which combines the strengths of two technologies (Web 2.0 and the Semantic Web), as a solution to reuse and extrapolate knowledge and software products across projects and organizations. Nevertheless, a full open world with the model of specification of all systems retrievable is not realistic. The future could reveal a trade-off in the global repository of system primitives description (like it exists in standardization) where each system is a black box to preserve copyrights but that gives its abstract description to communicate with this component or to encapsulate it in a SoS. This can be inspired by the TCP/IP approach that do not treat the content of packages but define the rules to send and receive the message. One future EIS challenge can be to standardize in between the systems rather than inside in order to facilitate the connections. 


\subsection{Next Gen EIS alignment with social networks}

Existing EIS frequently lacks to propose innovative information exchange between humans and are not being completely adapted with users' current practices. Human communication, and therefore data exchange, bypasses, in part, traditional EIS through social networks. For instance, the communication that occurs between human resources trough electronic social networks is not considered as part of the EIS process. In industrial engineering, although enterprises have reached the age of electronic communication, human unformal and direct communication is not sufficiently considered even as it remains a critical communication vector to transmit information. Also the understanding of the individual's capacity to react to information supplied by the EIS is not trivial. For instance adopting a change within an organization or ecosystem (implementation of a new EIS, new security instructions, etc.) and how the individual will use this new EIS is not easily anticipated. So understanding better how human behavior is react to information will permits a better EIS design. Research in social science domain gives significant results but the impact of information (social influence) on individuals within a social network is, mostly, statically modelled where the dynamic aspect, which occurs in the EIS information process, is not frequently tackled. For instance, the opinion of individuals is greatly influenced by a sequence of information gathered in its environment from other members of their social network. A specification model of the resources is one critical missing specification view of today's EIS.

Adding clear behavioral models resources will help in the global specification of the EIS, its verification and its reuse. Social networks models will complete the set of resource models. Researches have been initiated to observe the human behavior dealing with information in social networks. E.g. (Bouanan et al. 2015) have proposed dynamic models of individuals to simulate the propagation of information among a group of individuals and its influence on their behavior. In more details, it defined a set of models of individuals (e.g. nodes a-e in Fig. 6) characterized by a set of state variables and the mesh between the individuals within a multi dimension social network (e.g. dimension $1, \ldots, \mathrm{n}$ in Fig. 6). The author introduced information diffusion based on epidemic spreading algorithms and transposed them into the case of message propagation in an enterprise social network. Communications were done over different social networks and channels. The dimensions (e.g. dimension $1, \ldots, \mathrm{n}$ in Fig. 6) can represent the complexity of the different networks individuals belong to simultaneously in its professional life for instance. The human is placed, at work, ubiquitously in the different networks, it reflects the professional life. If we consider EIS resources, networks can be: co-workers, enterprise partners', friends within the enterprise, and other relatives. It can be assumed that specific diffusion rules for each network, for instance the confidence on the received information can be depending on the emitter and the network used to send the information. Then the human node can treat the information depending on its current behavior and relay in its turn the information. The social networks and human behavior models have already given simulation results. E.g. it reveals individuals that are key transmitter, identifies people that are not reachable by information because of their situation in the network (Bouanan et al. 2015). It can be considered as one most promising 
Fig. 6 Multidimensional social network

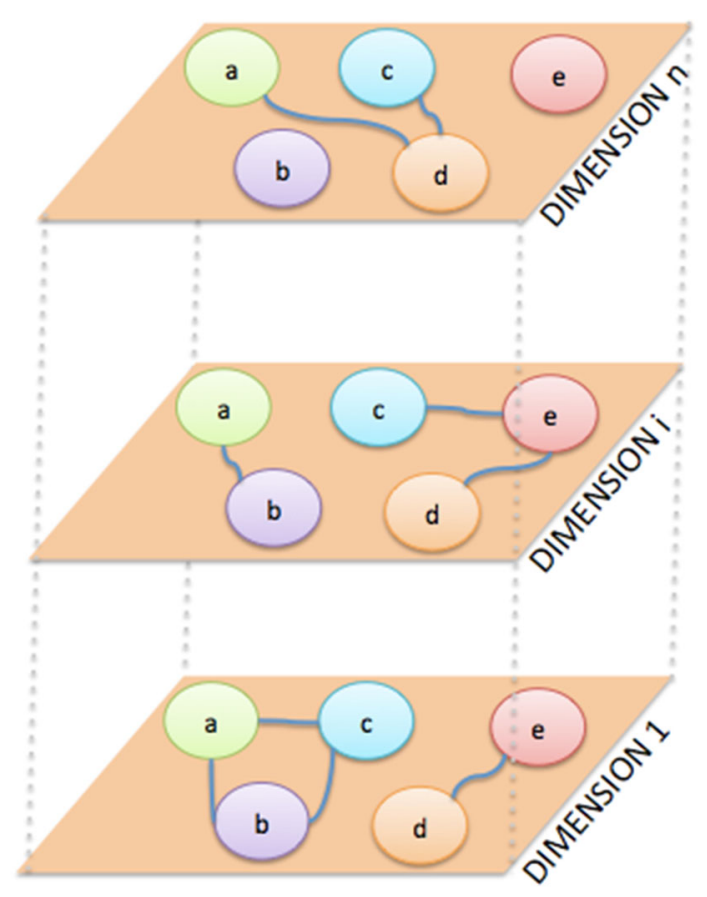

perspectives for Next Gen EIS. The future effort will consist in using these results to improve EIS resource interface and communication channels. These social networks models will complete the set of EIS models the increase the accuracy of the Next Gen EIS taking more into account the human direct and unformal communication. In the future, to keep being accurate to enterprise practices, these models can be improved to tackle new classes of diffusion rules depending on the category of the networks (e.g. extended enterprise network, freelance, etc.).

In addition to communication support, the web and social networks can be also a source of semantic data. They can be used as an input for ontological matching presented in Sect. 4.1. Lawson (2013) presented the potential of intelligent information coming from "only" structured information. For instance, Abel et al. (2011) presented the reuse of twitter posts for building users' profiles from the social web. As a perspective, we can assume that the future EIS will be able to query automatically surrounding systems to retrieve and deduce missing information from semantic relation that can exists between the data in its environment. It will deduce a list of missing information and will query human expert to complete its understanding of the data handled. The system could also stop the execution lifecycle on the detection of an exception point to correct with the intervention of the human in the loop contacted through a $\mathrm{SN}$ and then reiterate execution cycle steps. 


\subsection{Modelling indicators in Next Gen EIS}

The EIS is defined and developed to automate and control the information process. Many researches rely on the need, at exploitation level of this system, of efficient control information that cannot be efficient without defining and measuring performances (Laudon and Laudon 2012). This is done in order to supply the most useful information to support required decisions of business responsible. Literature reports several explicit definitions of performance measurement. One of these definitions (Neely et al. 2002) is that performance measurement "is the process of quantifying past actions, where measurement is the process quantification where past actions impact current performance ..." and act to "... achieve their defined objectives - that is, they perform-by satisfying their stakeholders' and their own wants and needs...". To achieve the performance tracking, a Performance Indicator (PI) is a quantified datum which measures the efficiency of actions in the frame of objective achievement (Ducq and Vallespir 2005). Bazoun et al. (2013) proposed a model transformation methodology that integrates PI definition. They transform conceptual models to down to DEVS model in order to simulate the model behavior and validate some scenario properties according to the reaching of defined PI.

The performance and interoperability measurement of an EIS becomes then a strong topic in the sense there are very few research works on it, mainly at the technical level as the Business Activity Monitoring. Few works have been carried out in the frame of interoperability performance measurement (Camara et al. 2014). They mainly define the measurement principles and generic indicators for organizational interoperability. Zacharewicz et al. (2009) and Camara et al. (2014) described that dynamic perspective through simulation is being an appropriate way to validate EIS process scenario. In addition, if there is a gap between the objective and the results obtained by simulation, value-based model analysis and optimization have to be addressed (Wang et al. 2010). Value is one the business point of view, and PIs are classified into business and technological ones, so each expected value should be connected with one or multiple business and technological PI. The idea is to observe virtually the evolution of these indicators thanks to simulation of the models. It will permit progressive validation of the models. For instance, in terms of software product line practice, Guo et al. (2012) gave a semantics-based model-driven approach to semi-automatically Derive Domain Functional Requirements (DFRs) from Product Functional Requirements (PFRs) by merging the same or similar PFRs and analyzing their commonality and variability.

In simulation, a main difficulty is to define at the same time coherent short and long term PI and related simulation principles that can be comprehensibly invoked from the EIS conceptual or technical models to reduce frequent re-modelling activities. Another drawback is that cloud computing implies EIS to handle heterogeneous and short lived content that need to be verified permanently accordingly the quality of service demanded by users in terms of connection to the network data and the security of this access. The next quality standard ISO 9000 version 2015 integrates risk management, is again another incitement to control risk indicator in the development of future EIS from the conceptual to the technical 
levels. From these postulates, an idea is to gain from reusing evolution and change management methods coming from human resources management that define short/long term objectives and functions. Another point could concern the benefit acquired from crisis and risk management that is a corollary to interoperability. A proposition could be to transpose these managements to technological and maybe piracy risks in EIS.

To operationalize these objectives, the distributed simulation is for sure a promising perspective where the reused parts of the EIS and new parts are combined and coupled thanks to interoperable virtual agents. For instance, a solution that reuses distributed simulation synchronization mechanism to couple agents has been developed by (Zacharewicz et al. 2010). This proposition has been extended with services calls and human resources that can be solicited during simulation thanks to man-machine interfaces (Ribault and Zacharewicz 2013). Here human takes part of an immersive virtual world in the form of augmented reality for validation of the behavior of the future global system. Again the simulation supports verifying the performance of the different couplings. To go further, the genetic algorithm, introduced by Holland (1975) and the ones that follow, can be a line to improve the performances and adapt faster the EIS to environment changes. Moreover, the coherence analysis between Business Indicators (BI) and Technical Indicators (TI) is also a strong point that has never been approached in the sense that traditional methods, such as Balanced Score Card (BSC), are more focused on the business and methods whereas Business Activity Monitoring are technical oriented. As a caution the BSC is mainly defined at Strategic level; but in the FITMAN project (FITMAN 2014) for instance a specific method has recently been initiated to combine TI and BI dedicated to generic and specific connectors for information systems.

These works plan to propose in a next step, within a short term period, to operationalize different BSC based PI in simulation. It will discover and compose PI from different domain thanks to matching interoperability and will also add social networks influence to gain in confidence with the future EIS. One step further will consist to define a simulation which can anticipate itself (according to PI) the need to update the least efficient part of the EIS (or deficient part), by browsing a base of potential replacement components that can improve the performances and switch the components to test the new performances of the hybrid real/simulated EIS.

\subsection{General perspective in the Next Gen EIS}

Hooft et al. (2005) recalled that in his later years, Einstein enounced a unified theory that would extend general relativity and provide an alternative to quantum theory. More recently a "theory of everything" has started to be developed (Hawking 2006). The theory of everything is general and still utopic, but it can inspire the future of EIS interoperability. More modestly, the Next Gen EIS could tend to be fully connected with its environment including all category of resources proposed in MDSEA. In computer science, pivot languages, such as XML, have been developed with similar objective of unification. But they are mainly focused on structuring the syntactical description. Also the common description of the meaning using ontology for instance has not reached a complete consensus at the moment but has been 
proposed in similar lines. This work will be long since some part of research community does not trust the contribution of semantics like it was already the case for pioneer logic of predicate and other AI initiatives of the late 80s'. Nevertheless, the authors bet that the future research works will be in charge to propose a semantic pivot and to make it being globally accepted. The languages will have the capacity to discover the similarity and will connect automatically to a novel languages introduced. Also the human natural language will be directly integrated and used to interface human and EIS. At the end, a final objective for Next Gen EIS will consist to choose between an explicit "e-Rosetta stone" language or just being able to accommodate and communicate on the fly thanks to short live shared paradigms (Zacharewicz et al. 2009).

\section{Conclusion}

Even if the research on interoperability and model driven approaches have permitted recent advances for specifying and developing EIS, the current research to design EIS is still facing barriers. The article has recalled existing model based approaches and methodologies, including: model alignment, model integration, reverse modeling, human modeling and modeling and simulation that can facilitate EIS specification. From this observation, it inventoried major barriers that still prevent the EIS to be interoperable. Then, from this state of the art and its current limitations, a novel Model Based Driven Conceptual Framework has been proposed. It proposes a general methodology that combines most recent advances in models based approaches. They have been distributed into semantic model alignment, model transformation, model discovery, social networks modeling and model performance indicators tracking using simulation. Then it detailed each of these the challenges for the Next Gen EIS. It concludes that the performance of the future EIS will depend on its semantics interoperability, integration, reusability, transformability and sociability skills. All of these attributes will be checked regarding the EIS environment using simulation tests and indicator measurements. This works permits projecting Next Gen EIS in a near and farther future. To generalize, the Next Gen EIS will support enterprise business in reaching expected qualities of the future enterprise that have been expressed in the recent EU future enterprise roadmaps including for instance the capacity to evolve more rapidly, being more agile, proactive and adding, in an almost autonomous way, new features. In the future it is assumed that these requirements, facing with reduced budgets and time are going to promote limited reengineering of the EIS and accordingly encouraging the model driven framework proposed. Smaller EIS improvement projects will emerge, focusing on reengineering a subpart of the EIS rather than redeveloping the full system. To finish, the human in the loop should be better considered in the EIS; not anymore only as an external user but rather completely involved through social networks as an embedded player in the EIS development and usage lifecycle. 


\section{References}

Abel F, Gao Q, Houben G-J, Tao K (2011) Semantic enrichment of twitter posts for user profile construction on the social web. Semanic Web Res Appl Lect Notes Comput Sci 6644:375-389

Ajaefobi JO, Weston RH (2005) Modelling human systems in support of process engineering. In: Integrating human aspects in production management. doi:10.1007/0-387-23078-5_1

Anaby-Tavor A, Amid D, Sela A, Fisher A, Zhang K, Jun OT (2008) Towards a model driven service engineering process. In: 2008 IEEE Congress on Services-Part I, pp 503-510

Arsanjani A, Ghosh S, Allam T, Abdollah T, Ganapathy S, Holley K (2008) SOMA: a method for developing service-oriented solutions. IBM Syst J 47(3):377-396

Bazoun H, Zacharewicz G, Ducq Y, Boyer H (2013) Transformation of extended actigram star to BPMN2.0 and simulation model in the frame of model driven service engineering architecture. In: DEVS 13 Proceedings of the symposium on theory of modeling and simulation-DEVS Integrative M\&S Symposium, Apr 2013, San Diego, United States

Bézivin J, Jouault F, Paliès J (2005) Towards model transformation design patterns. In: Proceedings of the First European Workshop on Model Transformations (EWMT 2005)

Borst WN (1997) Construction of engineering ontologies for knowledge sharing and reuse. Universiteit Twente

Bouanan Y, Ribault J, Forestier M, Zacharewicz G, Vallespir B (2015) Modeling and simulation of human reaction in a multidimensional social network. In: 5th IFAC symposium on information control problems in manufacturing-INCOM 2015, IFAC-PapersOnLine 48(3):592-597

Bourey JP, Grangel R, Doumeingts G, Berre A (2007) Deliverable DTG2.3 from the INTEROP project. Report on Model Driven Interoperability. http://interop-vlab.eu. Accessed 15 May 2013

C4ISR (1998) Architecture working group. Levels of information systems interoperability (LISI). http:// www.eng.auburn.edu/ hamilton/security/DODAF/LISI.pdf

Camara MS, Ducq Y, Dupas R (2014) A methodology for the evaluation of interoperability improvements in inter-enterprises collaboration based on causal performance measurement models. Int J Comput Integr Manuf 27(2):103-119

Camarinha-Matos LM, Macedo P, Oliveira AI, Ferrada F, Afsarmanesh H (2013) Collaborative environment for service-enhanced products. In: 2013 11th IEEE International Conference on Industrial Informatics (INDIN), pp 374-379, 29-31 July 2013

Chen D (2013) Framework for enterprise interoperability and maturity model (CEN/ISO 11354). Interoperability for enterprise software and applications, pp 15-22

Chen D, Vallespir B, Doumeingts G (1997) GRAI integrated methodology and its mapping onto generic enterprise reference architecture and methodology. Comput Ind 33(2):387-394

Chen D, Doumeingts G, Vernadat F (2008) Architectures for enterprise integration and interoperability: past, present and future. Comput Ind 59:647-659

Colomo-Palacios R, Gómez-Berbís JM, García-Crespo Á, Puebla-Sánchez I (2008) Software engineering 2.0: a social global repository based on semantic annotation and social web for knowledge management. In: The Open Knowlege Society. A computer science and information systems manifesto communications in computer and information science, vol 19, pp 468-475

Davenport TH (2013) Process innovation: reengineering work through information technology. Harvard Business Press, Harvard

Den Haan J (2008) 8 Reasons why model-driven approaches (will) fail, Posted on Jul 28, 2008. http:// www.infoq.com/articles/8-reasons-why-MDE-fails. Accessed on July 2015

Ducq Y, Vallespir B (2005) Definition and aggregation of a performance measurement system in three aeronautical workshops using the ECOGRAI method. Int J Prod Plann Control 16(2):163-177

Ducq Y, Agostinho C, Chen D, Zacharewicz G, Jardim-Goncalves R (2010) Generic methodology for service engineering based on service modelling and model transformation. In: Wiesner $\mathrm{S}$, Guglielmina C, Gusmeroli S, Doumeingts G (eds) Manufacturing service ecosystem: achievements of the European 7th Framework Programme FoF-ICT Project MSEE: Manufacturing SErvice Ecosystem (Grant No. 284860). Verlag-Mainz, 2014, pp 41-49. FInES Future Internet Enterprise Systems (FInES) Cluster-Cluster Book-ICT2010 EVENT VERSION, June 2010. http://cordis. europa.eu/fp7/ict/enet/documents

Euzenat J, Shvaiko P (2007) Ontology matching. Springer, Heidelberg

FInES Cluster, Future Internet Enterprise Systems, FInES Research Roadmap 2025 (2012). http://cordis. europa.eu/fp7/ict/enet/documents/fines-research-roadmap-v30_en.pdf. Accessed on July 2015 
FITMAN Project. http://www.fitman-fi.eu/. Website Accessed on July 2014

Fox MS, Barbuceanu M, Gruninger M (1996) An organisation ontology for enterprise modeling: preliminary concepts for linking structure and behaviour. Comput Ind 29(1):123-134

Giunchiglia F, Shvaiko P, Yatskevich M (2009) Semantic matching. In: Encyclopedia of database systems. Springer US, pp 2561-2566

Guo J, Wang Y, Zhang Z, Nummenmaa J, Niu N (2012) Model-driven approach to developing domain functional requirements in software product lines. IET Softw 6(4):391-401

Gusmeroli S (2008) Future Internet Service Offer, FISO Breakout Session, Global Service Delivery Platform Interactive Panel, FIA Madrid, 10 Dec 2008

Hawking SW (2006) The theory of everything: the origin and fate of the universe. Phoenix Books; Special Anniv

Holland JH (1975) Adaptation In Natural And Artificial Systems, University of Michigan Press

Hooft G, Susskind L, Witten E (2005) A theory of everything? Nature 433:257-259

Hu J, Huang L, Chang X, Cao B (2014) A model driven service engineering approach to system of systems. In: 2014 8th Annual IEEE Systems Conference, 31 Mar-3 Apr 2014, Ottawa, USA, pp 136-145

I-VLAB (2007) http://interop-vlab.eu/interop-vlab-network/presentation. Accessed on July 2015

Jardim-Goncalves R, Agostinho C, Steiger-Garcao A (2012) A reference model for sustainable interoperability in networked enterprises: towards the foundation of EI science base. Int $\mathrm{J}$ Comput Integr Manuf 25(10):855-873

Jouault F, Allilaire F, Bezivin J, Kurtev I (2008) ATL: a model transformation tool. Sci Comput Program 72(1-2):31-39

Kleppe AG, Warmer J, Bast W, Explained MDA (2003) The model driven architecture: practice and promise

Ko J, Song Y (2012) Graph Based Model Transformation Verification using Mapping Patterns and Graph Comparison Algorithm. Int J Adv Comput Technol 4(8):262-269

Kosanke K (1995) CIMOSA-overview and status. Comput Ind 27(2):101-109

Lampathaki F, Koussouris S, Agostinho C, Jardim-Goncalves R, Charalabidis Y, Psarras J (2012) Infusing scientific foundations into Enterprise Interoperability. Comput Ind 63(8):858-866

Laudon KC, Laudon JP (2012) Management information systems: managing the digital firm, vol 12. Pearson, New Jersey

Lawson J (2013) What's new in semantic enrichment. http://www.stm-assoc.org/2013_12_05_ EProduction_Lawson_Whats_new_in_semantics_OUP.pdf. Accessed on July 2015

LeMoigne J-L (1977) La théorie du système général. Théorie de la modélisation, PUF

Leue S, Mehrmann L, Rezai M (1998) Synthesizing software architecture descriptions from message sequence chart specification. In: Proceedings of the 13th IEEE International Conference on Automated Software Engineering (ASE98). IEEE Computer Society Press, pp 192-195

Li J, Zhan D, Nie L, Xu X (2012) An approach for validating semantic consistency of model transformation Based on pattern. In: van Sinderen $\mathrm{M}$ et al (eds) Enterprise Interoperability. Lecture Notes in Business Information Processing, vol 122. Springer, Berlin Heidelberg, pp 161-171

Li J, Zhan D, Nie L, Xu X (2013) An approach for defining and validating property preservation constraints for model transformation. J Comput Inf Syst 9(4):1271-1278

Lin H-L, Hung S-S, Tsaih D (2009) Modeling service-driven architecture for distributed enterprise portal for maintaining path consistency. In: SEPADS'09, 8th WSEAS international conference on software engineering, parallel and systems, pp 135-143

Mesarovic MD, Takaraha Y (1975) General systems theory: mathematical foundations

MSEE (2014) Manufacturing service ecosystem. Research project FP7 FoF-ICT-2011.7.3. http://www. msee-ip.eu. Accessed on July 2015

Neely A, Adams C, Kennerley M (2002) The performance prism-the scorecard for measuring and managing business success. Prentice Hall, Upper Saddle River

NIST (2014) http://www.nist.gov/el/msid/mbesummit_2014.cfm. Accessed March 2015

OMG (2003) MDA guide version 1.0. OMG standard. document number: omg/2003-05-01. Accessed 15 May 2013. http://www.omg.org/cgi-bin/doc?omg/03-06-01. Accessed on July 2015

OMG (2013) Architecture-driven modernization task force. http://adm.omg.org/. Accessed 15 Jan 2015

Panetto H, Molina A (2008) Enterprise integration and interoperability in manufacturing systems: trends and issues. Comput Ind 59(7):641-646

Pietsch P, Müller K, Rumpe B (2014) Model matching challenge: benchmarks for ecore and bpmn diagrams. arXiv preprint arXiv:1408.5693 
Ribault J, Zacharewicz G (2013) Orchestrating the interoperability workflow within a transport simulation platform. In: Proceedings of I3 M: the 10th international multidisciplinary modelling and simulation multiconference

Roque M, Vallespir B, Doumeingts G (2006) Network-centric collaboration and supporting frameworks. IFIP International Federation for Information Processing, UEML: Coherent Languages and Elementary Constructs Determination, Springer US

Shvaiko P, Euzenat J (2013) Ontology matching: state of the art and future challenges. IEEE Trans Knowl Data Eng 25(1):158-176

Silingas D, Why MDA (2013) Fails: analysis of unsuccessful cases. Code Generation Conference, Cambridge, UK, 10-12 April 2013

Song F, Zacharewicz G, Chen D (2013) An ontology-driven framework towards building enterprise semantic information layer. Adv Eng Inform 27:38-50

Souba W (2011) The language of discovery. J Biomed Discov Collab 6:53-69

Sun Z, Wang J, He K, Xiang S, Yu D (2010) A model transformation method in service-oriented domain modeling. In: 21st Australian Software Engineering Conference, pp 107-116

Tolk A, Diallo SY, Turnitsa CD (2006) Ontology driven interoperability-M\&S applications. Whitepaper in support of the I/ITSEC Tutorial 2548, VMASC Report, Old Dominion University, Suffolk, VA

Tu Z, Zacharewicz G, Chen D (2014) Building an HLA federated interoperable framework from legacy information systems. Int J Comput Integr Manuf 27(4):313-332

Van Der Aalst WMP (2011) Process mining: discovery, conformance and enhancement of business processes. Springer, Berlin, ISBN 978-3-642-19344-6

Wang Z, Xu X (2012) A sharing-based service composition and scheduling approach for the optimization of resource utilization. Serv Oriented Comput Appl (SOCA) 6(1):15-32

Wang J, He K, Gong P, Wang C, Peng R, Li B (2008) RGPS: a unified requirements meta-modeling frame for networked software. In: The 3rd international workshop on applications and advances of problem frames (IWAAPF'08), 10 May 2008, Leipzig, Germany, pp 29-35

Wang Z, Xu X, Ma C, Liu A (2010) Service value meta-model: an engineering viewpoint. In: 6th international conference on interoperability for enterprise software and applications (I-ESA 2010). Coventry, UK, 24-26 March 2010

Wang Y, Zacharewicz G, Chen D, Traoré MK (2015) A proposal of using DEVS model for process mining. EMSS 2015 part of I3 M 2015 Bergeggi, Italy

Wiederhold G (1992) Mediators in the architecture of future information systems. Computer 25(3):38-49

$\mathrm{Xu} \mathrm{X}$, Wang Z (2008) VASEM: value-aware service engineering and methodology. In: Proceedings of the 20th IFIP World Computer Congress, 7-10 Sept 2008, Milano, Italy, pp 277-286

Xu X, Wang Z (2011) State of the art: business service and its impacts on manufacturing. J Intell Manuf 22(5):653-662

Zacharewicz G, Chen D, Vallespir B (2009) Short-lived ontology approach for agent/HLA federated enterprise interoperability. In: International conference on interoperability for enterprise software and applications. IESA '09, Beijing, China, pp 329-335

Zacharewicz G, Hamri A, Frydman C, Giambiasi N (2010) A generalized discrete event system (GDEVS) flattened simulation structure: application to high-level architecture (HLA) compliant simulation of workflow. Simulation 86(3):181-197

Zeigler BP, Kim TG, Praehofer H (2000) Theory of modeling and simulation, 2nd edn. Academic Press, Inc., Orlando

Zhang X, He K, Wang J, Liu J, Wang C, Lu H (2012) On-demand service-oriented MDA approach for SaaS and Enterprise Mashup Application Development. In: 2012 International conference on cloud computing and service computing, pp 96-103

Zhu J, Tian Z, Li T, Sun W et al (2004) Model-driven business process integration and management: a case study with the Bank SinoPac regional service platform. IBM J Res Dev 48(5/6):649-669

Zhu Y, Fei L, Yang N (2013) Trustworthy software development based on model driven architecture. In: Yang Y, Ma M, Liu B (eds) Information Computing and Applications. Communications in Computer and Information Science, vol 391. Springer, Berlin Heidelberg, pp 193-202 